\title{
Green Synthesis of Silver Nanoparticles Using Ocimum basilicum L. and Hibiscus sabdariffa L. Extracts and Their Antibacterial Activity in Combination with Phage ZCSE6 and Sensing Properties
}

\author{
Abdallah S. Abdelsattar ${ }^{1,2} \cdot$ Toka A. Hakim $^{1} \cdot$ Nouran Rezk $^{1} \cdot$ Warda M. Farouk $^{1}$ - Yara Y. Hassan ${ }^{1}$. \\ Shrouk Mohamed Gouda ${ }^{1} \cdot$ Ayman El-Shibiny ${ }^{1,3}$
}

Received: 4 December 2021 / Accepted: 12 January 2022 / Published online: 30 January 2022

(C) The Author(s) 2022

\begin{abstract}
One of the dangerous pathogens that display high resistance to antibiotics is Salmonella enterica (S. enterica), which infects humans and animals. In this study, a new approach was proposed to fight antibiotic-resistant bacteria by using silver nanoparticles (AgNPs) with adding the phage ZCSE6. The biosynthesized AgNPs were characterized by analysis of spectroscopy profile of the UV-Vis, visualize the morphology, and size with transmission electron microscopy. Both minimum inhibitory concentration (MIC) and minimum bactericidal concentration (MBC) were assessed. In addition, the AgNPs were able to control the biofilm formation of S. enterica, also, heavy metals detection by AgNPs and their application in milk. UV-Vis spectra showed a surface resonance peak of 400 and $430 \mathrm{~nm}$ corresponding to the formation of AgNPs capping with Ocimum basilicum L. and Hibiscus sabdariffa L., respectively. The MIC and MBC values were $6.25 \mu \mathrm{g} / \mathrm{ml}$ to inhibit the growth of $S$. enterica and $12.5 \mu \mathrm{g} / \mathrm{ml}$ from killing the bacteria and it was decreased to $1.5 \mu \mathrm{g} / \mathrm{ml}$ when combined with the phage. In the present study, AgNPs were combined with phage ZCSE6 to obtain a synergetic antimicrobial activity. Moreover, it increases the milk's shelf-life and senses the $\mathrm{Cd}^{2+}$ at a concentration of $1 \mathrm{mM}$ in the water.
\end{abstract}

Abdallah S. Abdelsattar and Toka A. Hakim have contributed equally to this work.

Ayman El-Shibiny

aelshibiny@zewailcity.edu.eg

1 Center for Microbiology and Phage Therapy, Zewail City of Science and Technology, Giza 12578, Egypt

2 Center for X-Ray and Determination of Structure of Matter, Zewail City of Science and Technology, Giza 12578, Egypt

3 Faculty of Environmental Agricultural Sciences, Arish University, Arish 45511, Egypt 


\section{Graphical Abstract}

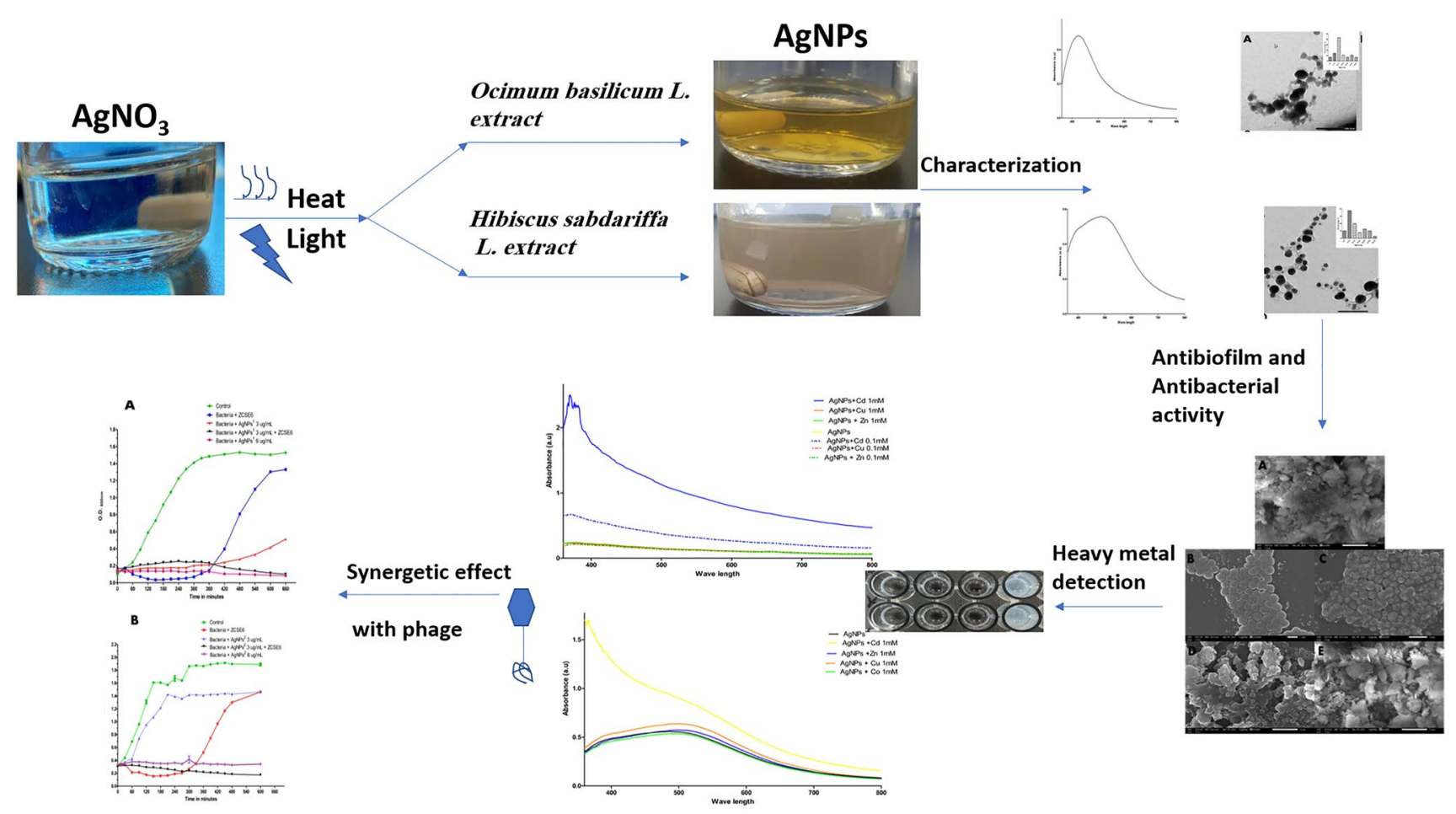

Keywords Silver nanoparticles $\cdot$ Bacteriophage $\cdot$ Multi-drug resistant

\section{Introduction}

The development of new and effective antimicrobials to combat diseases caused by antibiotic-resistant bacteria has sparked attention in recent decades due to the growing resistance rate among pathogenic bacteria. One of the highly spreading pathogens in humans and other living organisms is Salmonella which causes many diseases and money loss. Salmonella is a Gram-negative, facultatively anaerobic, non-capsulated, and non-spore-forming bacterium with many serotypes and belongs to the Enterobacteriaceae family [1]. One of the most known diseases caused by Salmonella is Typhoid disease, which was involved in many death cases and an epidemic in the past [2]. Moreover, non-typhoid Salmonella servers (NTS) are associated with several immune diseases in humans like HIV [3]. Salmonella can infect humans through contaminated plants and poultry since they are the main hosts as a foodborne pathogen [4]. To fight pathogenic bacteria, antibiotics are still used as the main treatment. However, due to the excessive use of antibiotics, the bacteria undergo some genetic variations as a defense mechanism which causes resistance to many antibiotics [5]. The bacterial resistance to antibiotics serves as the main hindrance to its usage. One of the most known antibiotic-resistant strains is the multidrug-resistant (MRD) Salmonella which is prevalent and widely transmitted from different food sources to humans as a foodborne disease [6].

To overcome the challenge of antibiotic resistance, scientists are trying to find alternatives for antibiotics. Bacteriophages are presented as a good alternative to antibiotics due to their abundance, effectiveness, and their simple structure and genome that allow for different characterization, sequencing, and manipulation. There is a huge number of phages and each phage is quite specific in its targeting and has a narrow host range that can be used to treat pathogenic bacteria such as Salmonella [7, 8]. Phages can reproduce only in the presence of their host bacteria and can widely spread all over the body including the infection site. The small scale of phage helps them to enter areas that cannot be penetrated with the molecules of drugs. Once at the infection site, the phage's exponential growth can lead to lower and less regular dose treatment than antibiotic therapy would take [9]. Phages only invade bacterial cells and do not affect mammalian cells; the host does not have a chance of toxicity. The isolation of new effective phages is relatively fast and inexpensive, in comparison to the production of antibiotics, which needs millions of dollars and years of study for an effective antibiotic drug to be created [10]. On the other 
hand, phages have many drawbacks like the occurrence of negative immunological responses, the difficulty of using the phages to kill the bacteria clinically, possible bacterial resistance to the phage, the possible occurrence of antibiotic resistance because of phages, and most importantly; secondary infection and co-infection [10]. To improve phage efficiency, recent researches are directed towards supporting the phages with other substances to reach a synergy that would decrease the incidence of phage resistance [11].

Another alternative for antibiotics is the use of antibacterial agents like silver ions and AgNPs [12]. Silver is recognized for its anti-microbial activity against a broad spectrum of pathogenic microorganisms. Silver has been used since ancient times due to its medicinal properties and now the activity and application of AgNPs are being explored in biotechnology medical research. The formation of small nanoparticles with proper stability and distribution is vital for active and efficient nanoparticles [13]. The biochemical processes of AgNPs with Gram-positive and Gram-negative bacteria are still unknown, and there are special properties for every nanoform of the silver with different resistance mechanisms and different modes of action. AgNPs are shown to have inhibition effects on MDR Salmonella among other bacteria by recognizing and damaging the bacteria by causing cellular toxicity [14]. However, there are health concerns while using the AgNPs due to nanotoxicity and the damage of the internal human organs like kidneys, liver, blood cells, intestinal tract, eyes, and skin. The reason for the toxicity is due to the free silver particles in the body [15], and to overcome this toxic issue scientists are trying to use natural products to prepare AgNPs. The green synthesis of AgNPs such as Ocimum basilicum L. Hibiscus sabdariffa, L. leaf extract was used as reducing agents and nanoparticles stabilizers. Ocimum basilicum L. and Hibiscus sabdariffa L. belong to a group of medicinal and aromatic plants of economic value worldwide. Also, used in folk medicine, and various pharmaceutical applications. [16]. The natural products that can be used to prepare AgNPs include Ocimum basilicum and Hibiscus sabdariffa $\mathrm{L}$. which showed antibacterial activity against Aggregatibacter actinomycetemcomitans [17]. Furthermore, the combination of phages with AgNPs coated by Ocimum basilicum L. and Hibiscus sabdariffa $\mathrm{L}$. as natural products would enhance their biocontrol efficiency and decrease bacterial resistance.

In addition, there are many biological applications of AgNPs. Due to their unique properties, AgNPs have been used extensively in household tools, in the field of health and food preservation, in environmental and biomedical applications. Several reviews have been devoted to the different applications of AgNPs. there are many applications of AgNPs in various biological and biomedical applications, such as antibacterial, antifungal, antiviral, and antiinflammatory applications [18]. The aim of this study is to illustrate the synergetic effect against the $S$. enterica combined with AgNPs coating with Ocimum basilicum L. and Hibiscus sabdariffa L. and phage ZCSE6. Then evaluated the sensing properties of biosynthesized AgNPs for the detection of heavy metals and the antibacterial activity in combination with phage.

\section{Materials and Methods}

\subsection{Preparation of Ocimum basilicum L. and Hibiscus sabdariffa L.extracts}

The Egyptian leaves of Ocimum basilicum L. and the airdried flowers of Hibiscus sabdariffa L. were locally collected and rinsed thoroughly with tap water followed by doubled distilled water to eliminate all dust and visible debris. The extraction was conducted as described previously [19, 20 ] with some modifications. Briefly, $50 \mathrm{ml}$ of $99.5 \%$ ethanol was used to extract the active components. Then, the ethanolic extracts of Ocimum basilicum L. and Hibiscus sabdariffa $\mathrm{L}$. were left at room temperature for 2 days before transferring them into clean containers and stored at $4-8{ }^{\circ} \mathrm{C}$.

\subsection{Biosynthesis of AgNPs}

The AgNPs were biosynthesized by using the ethanolic extraction of Ocimum basilicum L. and Hibiscus sabdariffa L. as a coating agent as was described before [21, 22] with some modifications. Briefly, $20 \mathrm{ml}$ of $1 \mathrm{mM}$ silver nitrate $\left(\mathrm{AgNO}_{3}\right)$ (Techno pharmachem, India) were prepared with clean and deionized water, and $300 \mu \mathrm{l}$ of the pure Ocimum basilicum L. and Hibiscus sabdariffa L. ethanolic extraction were added to the $\mathrm{AgNO}_{3}$ solution. Then, the solution was left around $5 \mathrm{~h}$. on the hot plate at a stable temperature of $85{ }^{\circ} \mathrm{C}$ with steering. The color change confirmed the complete reduction of $\mathrm{AgNO}_{3}$ to AgNPs, and then the sample was collected for further characterization.

\subsection{Characterization of AgNPs}

The spectrophotometer (Jenway 7200 visible spectrophotometer) was used to determine the production of AgNPs. Exactly, $1 \mathrm{ml}$ of the diluted supernatant of the Ocimum basilicum L. and Hibiscus sabdariffa L. AgNPs were placed in a cuvette then inserted in a UV-Vis spectrophotometer using the wavelength range of $340-800 \mathrm{~nm}$ to obtain the UV-Visible spectra of the sample. TEM was used to examine the size and morphology of biosynthesized AgNPs by loading the AgNPs on the copper grids and left to dry. Then, the TEM (JEOL 1230) was used to examine the sample. Dynamic Light Scattering (DLS) (Zetasizer Nano ZS, Malvern, UK) was used for the determination of the size 
distribution of the AgNPs, and the raw data were analyzed by Zetasizer software. The results from Zetasizer were obtained without dilution with deionized water in addition to measuring the zeta potential of AgNPs. The samples were prepared before the measurement by sonication for $5 \mathrm{~min}$. The analysis was conducted to deduce the particle size, size distribution, and charge.

\subsection{Antibacterial Effect of AgNPs Using Disc, and Well Diffusion}

S. enterica serovar Enteritidis (CMPZCSB1) was used in this study. Stocks were kept at $-80{ }^{\circ} \mathrm{C}$ in $20 \%$ (v/v) glycerol until needed. Bacterial strains were cultivated overnight at $37^{\circ} \mathrm{C}$ on Tryptone Soya Agar (TSA). The antimicrobial activity was evaluated by the disc and well Diffusion methods. The antimicrobial activity of biosynthesized AgNPs was evaluated against $S$. enterica strain by agar well diffusion technique according to Ramadan et al. [23]. Briefly, a day culture of the bacteria was prepared by adding a single colony to $3 \mathrm{ml}$ of Tryptone Soya Broth (TSB) and incubated at $37{ }^{\circ} \mathrm{C}$ for $4 \mathrm{~h}$. Then, $0.5 \mathrm{ml}$ of the bacterial culture was swapped on solid TSA plates. Once the upper inoculated agar medium was air-dried, different wells with a diameter of $(6 \mu \mathrm{m})$ were made using sterile tips. In the first well, 20 $\mu \mathrm{l}$ of kanamycin was added as a positive control. Then the second well was left without any component as a negative control. Different concentrations ( $100 \mu \mathrm{g} / \mathrm{ml}, 50 \mu \mathrm{g} / \mathrm{ml})$ of AgNPs capped with Ocimum basilicum L. and Hibiscus sabdariffa L. were loaded to the last two wells. Antibacterial activity was determined by averaging the diameter of the inhibition zone formed around the center of each well. The disc diffusion was performed according to Ajitha et al. [24]. Briefly, filter paper discs (about $6 \mathrm{~mm}$ in diameter) were placed on the TSA agar surface swapped with the bacterial culture. After that, $10 \mu \mathrm{l}$ of AgNPs were added with different concentrations $(50 \mu \mathrm{g} / \mathrm{ml}$ and $100 \mu \mathrm{g} / \mathrm{ml})$. Each extract of Ocimum basilicum and L. Hibiscus sabdariffa L. was also used throughout the experiment as a negative control.

\subsection{Heavy Metal Detection}

Four different types of heavy metals: cadium chloride $\left(\mathrm{CdCl}_{2}\right)$, Cupric Sulphate $\left(\mathrm{CuSO}_{4}\right)$, Zinc Nitrate $\left(\mathrm{Zn}\left(\mathrm{NO}_{3}\right)\right.$, and Cobalt(II) Sulphate $\left(\mathrm{CoSO}_{4}\right)$ were used to detect the specificity of sensing the colorimetric property of AgNPs. To demonstrate the effect of $\mathrm{CdCl}_{2}, \mathrm{CuSO}_{4}, \mathrm{Zn}\left(\mathrm{NO}_{3}\right)$, and $\mathrm{CoSO}_{4}$ on AgNPs, $100 \mu \mathrm{M}$ and $1 \mathrm{mM}$ of each type of heavy metal $\left(\mathrm{CdCl}_{2}, \mathrm{CuSO}_{4}, \mathrm{Zn}\left(\mathrm{NO}_{3}\right)_{2}\right.$, and $\left.\mathrm{CoSO}_{4}\right)$ were added one at a time to AgNPs coated with Ocimum basilicum L., and Hibiscus sabdariffa L. then the mixture was allowed to stand for $5 \mathrm{~min}$ at room temperature. Then, AgNPs with heavy metals were placed in a cuvette with a
$1 \mathrm{~cm}$ path length and inserted in a UV-Vis spectrophotometer using the wavelength range of $340-800 \mathrm{~nm}$ to obtain the UV-Vis spectra of the samples. Moreover, two different concentrations $(0.1$ and $1 \mathrm{mM})$ of the heavy metal as negative control were tested by distilled water to know if there are any spectra for heavy metals.

\subsection{Phage Combination with AgNPs}

\subsubsection{Phage Stability with AgNPs}

The Siphoviridae phage ZCSE6 was employed in combination with AgNPs to evaluate their potential synergetic effects. Exactly, $100 \mu \mathrm{l}$ of phage at $10^{9} \mathrm{PFU} / \mathrm{ml}$ was added to an Eppendorf containing $100 \mu \mathrm{l}$ of AgNPs and incubated for $48 \mathrm{~h}$ at $4{ }^{\circ} \mathrm{C}$ to examine the stability of phage ZCSE6. By using double-agar overlay plaque assays, the phage titer was determined before and after incubation to test its stability [25]. Seventy $\mu \mathrm{l}$ of the bacterial culture was added to $4 \mathrm{ml}$ of molten $0.5 \%$ top agar and then poured on the TSA plates. After solidifying, $10 \mu \mathrm{l}$ of 10-fold serially-diluted phage mixed with biosynthesized AgNPs and spotted on the bacterial lawn. The plates were left to dry before being incubated overnight at $37^{\circ} \mathrm{C}$.

\subsubsection{MIC and MBC of AgNPs}

The MIC test was performed in 96-well round-bottom microtiter plate using the standard broth microdilution method [26]. MBC test was performed by plating the suspension from each well of microliter plates into TSA plate. The plates were incubated at $37{ }^{\circ} \mathrm{C}$ for $24 \mathrm{~h}$. The lowest concentration with no visible growths on the TSA plate was taken as MBC value [27]. S. enterica was grown on TSA plates. Then, a fresh colony (around $10^{6} \mathrm{CFU}$ ) was inoculated in the TSB and incubated at $37{ }^{\circ} \mathrm{C}$ for $30 \mathrm{~min}$. Exactly, $100 \mu \mathrm{l}$ of bacterial culture were added to $100 \mu \mathrm{l}$ of AgNPs in the empty 96-well and adjusted to be diluted by two folds in each well with different concentrations $0.75,1.5,3.1,6.2,12.5,25,50 \mu \mathrm{g} / \mathrm{ml}$. The MIC value was taken at the lowest concentration of antibacterial agents that inhibits the growth of bacteria. After the determination of the MIC for biosynthesized AgNPs, the MBC test was conducted by plating the suspension from each clear well of microtiter plates into the TSA plate. The plates were incubated at $37^{\circ} \mathrm{C}$ for $24 \mathrm{~h}$. The lowest concentration of AgNPs reduced the titer lower than the limit of detection (around $10^{3} \mathrm{CFU}$ ). All steps were applied in triplicate. Then, all steps for MIC and MBC were repeated in combination with phage ZCSE6 or by using the phage alone in different titers. 


\subsubsection{In Vitro Time-Kill Assay}

The time-killing curve is used to test the antimicrobial effect over time. One $\mathrm{ml}$ of $S$. enterica in TSB $\left(10^{8} \mathrm{CFU}\right)$ at 0.35 $\mathrm{OD}_{600}$ was prepared in a cuvette as a positive control. In addition to another six cuvettes; one containing the bacteria with phage ZCSE6 at Multiplicity of Infection (MOI) of 0.1 two cuvettes containing the bacteria with different concentrations of 3 and $6 \mu \mathrm{g} / \mathrm{ml}$, two had a combination of phage at MOI of 0.1, AgNPs with different concentrations ( 3 and $6 \mu \mathrm{g} / \mathrm{ml}$ ), and bacteria, and the last one contained the negative control that contains fresh TSB without bacterial growth. All cuvettes were incubated at $37{ }^{\circ} \mathrm{C}$ with gentle shaking for $600 \mathrm{~min}$. During the incubation period, the samples were analyzed by measuring the $\mathrm{OD}_{600}$ at different points using a spectrophotometer for analysis of the sample. The experiment was repeated for biosynthesized AgNPs by Ocimum basilicum L. and Hibiscus sabdariffa L.

\subsubsection{Synergistic Effect of Phage ZCSE6 and AgNPs in Milk}

To confirm the synergetic effect of phage ZCSE6 with the two biosynthesized silver nanoparticles. First of all, the raw milk was treated with heat $\left(110{ }^{\circ} \mathrm{C}\right.$ for $\left.10 \mathrm{~min}\right)$ to prevent any source of contamination. Seven groups were produced as the following: the first group was the pure milk as a negative control, the second one was infected milk with of $S$. enterica $\left(10^{6} \mathrm{CFU}\right)$ culture as a positive control, the third one is infected milk was treated with phage ZCSE6 at MOI of 1, and the fourth and fifth samples were infected milk with bacterial culture $\left(10^{6} \mathrm{CFU}\right)$ that are treated with $3 \mu \mathrm{g} / \mathrm{ml}$ of AgNPs with Ocimum basilicum L., and Hibiscus sabdariffa L., respectively. The sixth and seventh samples contained milk with bacterial culture $\left(10^{6} \mathrm{CFU}\right)$ and were treated with the MOI 1 of phage ZCSE6 and $3 \mu \mathrm{g} / \mathrm{ml}$ of two biosynthesized AgNPs with Ocimum basilicum L., and Hibiscus sabdariffa L., respectively. The milk was incubated at room temperature at $25^{\circ} \mathrm{C}$, and then samples were tested after $24 \mathrm{~h}$ of incubation.

\subsubsection{Effect of the AgNPs on the Shelf-Life of the Milk}

To examine the prolongation shelf-life stability of milk by using AgNPs, nine groups were divided as follows: first and second groups were negative control with pure milk at $4{ }^{\circ} \mathrm{C}$, $25^{\circ} \mathrm{C}$ respectively. The third group was positive control (bacterial culture in milk; $10^{6} \mathrm{CFU}$ ) at $25^{\circ} \mathrm{C}$. The fourth and fifth groups were infected with the bacteria $\left(10^{6} \mathrm{CFU}\right)$ and treated with $6.2 \mu \mathrm{g} / \mathrm{ml}$ AgNPs coating with Ocimum basilicum L., and Hibiscus sabdariffa L. respectively. Sixth and seven groups were infected with the bacteria $\left(10^{6} \mathrm{CFU}\right)$ and treated with $3 \mu \mathrm{g} / \mathrm{ml}$ of both types of AgNPs. The eighth and ninth groups were infected with bacteria at $10^{6} \mathrm{CFU} / \mathrm{ml}$ then treated by
MOI of 1 phage ZCSE6 and $3 \mu \mathrm{g} / \mathrm{ml} \mathrm{AgNPs} \mathrm{of} \mathrm{both} \mathrm{types.}$ All groups were incubated at $25^{\circ} \mathrm{C}$ for 7 days to test the texture and $\mathrm{pH}$ of the milk except the first group was kept at $4{ }^{\circ} \mathrm{C}$.

\section{Results}

\subsection{The Formation of Biosynthesized AgNPs}

The formation of AgNPs Capping with Ocimum basilicum L. was confirmed by the color changing from colorless to the pale-yellow color solution after $5 \mathrm{~h}$ (Fig. 1A, B). Also, the Hibiscus sabdariffa $\mathrm{L}$. extract caused a change in color from colorless to brown (Fig. 1C, D), indicating the fast reduction of $\mathrm{Ag}^{+}$to $\mathrm{Ag}^{0}$ in $\mathrm{AgNO}_{3}$ solution.

\subsection{The UV-Vis Spectrum}

UV-Vis spectroscopy is used for the primary characterization of biosynthesized nanoparticles also used to monitor the synthesis and stability of AgNPs. The synthesis of AgNPs in the solution was confirmed by the results of UV-Vis spectrophotometers. The UV-Vis spectrum resulted in a single peak with a maximum absorption peak between 400 and 430 nm with Ocimum basilicum L. extract (Fig. 2A). Also, the spectrum of SPR ranged from 400 to $500 \mathrm{~nm}$ of the absorption band with Hibiscus sabdariffa L. extract (Fig. 2B). The excitation of SPR is visible in this spectrum, indicating the creation of silver nanoparticles. AgNPs have unique optical properties that make them strongly interact with specific wavelengths of light.

\subsection{Characterization of Shape, Size, and Charge}

The TEM images clearly showed the two biosynthesized silver nanoparticles with sizes less than $35 \mathrm{~nm}$; one with $O c i$ mum basilicum $\mathrm{L}$. showed a high frequency of sizes between 10 and $15 \mathrm{~nm}$ (Fig. 3A), and the other one with Hibiscus sabdariffa $\mathrm{L}$. showed a high frequency of sizes between 5 and $10 \mathrm{~nm}$ (Fig. 3B) extracts were highly mono-dispersed in spherical shapes. The zeta potential of the AgNPs with Ocimum basilicum L. extract displayed a sharp peak at -10.2 $\mathrm{mV}$ (Fig. 3C), while the potential of the AgNPs with Hibiscus sabdariffa L. extract displayed a sharp peak at -19.1 $\mathrm{mV}$ (Fig. 3D). The data from the zetasizer for both AgNPs ensured that all the sizes were less than $100 \mathrm{~nm}$ (Supplementary data).

\subsection{Antibacterial Effect of AgNPs Using Disc and Well Diffusion and Direct Spotting}

The antibacterial effect of the AgNPs was evaluated against $S$. enterica by measuring the inhibitory zone's diameter in mm (Fig. 4A-D). Direct spotting provides 
Fig. 1 Flask $\mathbf{A}$ and $\mathbf{C}$ represent the color changes at time 0 (before) for AgNPs capping with Ocimum basilicum L. and Hibiscus sabdariffa L. extract respectively, while Flask $\mathbf{B}$ and D represent the biosynthesis of AgNPs after $5 \mathrm{~h}$


Fig. 2 The UV-Visible spectra of AgNPs coated by Ocimum basilicum L. extract (A) and Hibiscus sabdariffa L. extract (B)

information on whether the concentration has an antibacterial effect or not. The largest inhibition zone has resulted from kanamycin (positive control). The diameters of the inhibitory zones of different concentrations $(50 \mu \mathrm{g} / \mathrm{ml}$ and $100 \mu \mathrm{g} / \mathrm{ml}$ ) of biosynthesized AgNPs were measured (Table 1). Ocimum basilicum L. and Hibiscus sabdariffa
L. extracts did not produce any inhibitory zones like the negative control, indicating that they did not control the bacterial growth. However, AgNPs displayed a higher efficiency to inhibit the growth of the bacterial culture (Fig. 4; Table 1). 


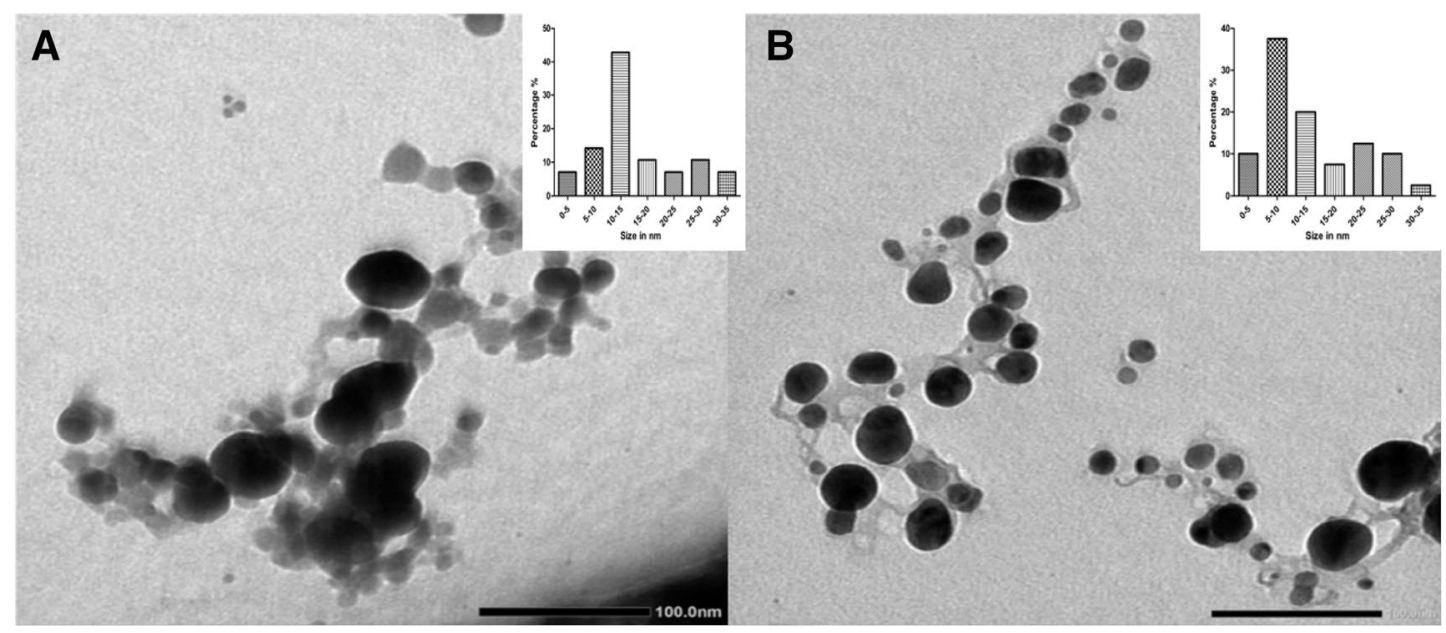



Fig. 3 TEM images with a scale bar of $100 \mathrm{~nm}$ (A), zeta potential equal to $-10.2 \mathrm{mV}(\mathbf{C})$ of the biosynthesized AgNPs with Ocimum basilicum L. extract. TEM images with a scale bar of $100 \mathrm{~nm}(\mathbf{B})$,

\subsection{Sensing the Heavy Metal}

During the reaction, the solution turned to white color. The intensity of this color gradually increased with the increase of $\mathrm{CdCl}_{2}$ concentration in both AgNPs with Ocimum basilicum L. and with Hibiscus sabdariffa L. extracts. The absorbance spectrum of the $\mathrm{CdCl}_{2}$ was higher and more symmetrical compared to the rest of heavy metals, $\mathrm{CuSO}_{4} \mathrm{Zn}\left(\mathrm{NO}_{3}\right)_{2}$, and $\mathrm{CoSO}_{4}$, at the two different concentrations ( 0.1 and 1 $\mathrm{mM})$ (Fig. 5).

\subsection{Phage Combination with AgNPs}

\subsubsection{Phage Stability with AgNPs}

Our results showed that the phage ZCSE6 revealed higher stability when combined with AgNPs before and after
D



zeta potential equal to $-19 \mathrm{mV}$ (D) of the biosynthesized AgNPs with and with Hibiscus sabdariffa L. extract

incubation for $48 \mathrm{~h}$ with the $92 \mu \mathrm{g} / \mathrm{ml}$ of AgNPs at $4{ }^{\circ} \mathrm{C}$. Although the high concentration of both biosynthesized AgNPs combined with phage ZCSE6, the phage titer was not affected. Before the incubation, the titer of the phage ZCSE6 was $4 \times 10^{8} \mathrm{PFU} / \mathrm{ml}$ and after the incubation, the titer of phage with AgNPs capped with Ocimum basilicum L. was around $1.3 \times 10^{8} \mathrm{PFU} / \mathrm{ml}$ and with Hibiscus sabdariffa L. was around $2.6 \times 10^{8} \mathrm{PFU} / \mathrm{ml}$ (Fig. 6). The $t$ test for those groups compared to the controls showed a non-significant change in the phage titer.

\subsubsection{MIC and MBC}

After $24 \mathrm{~h}$ of incubation at $37{ }^{\circ} \mathrm{C}$, the minimum concentration of AgNPs that was able to inhibit the growth of $S$. enterica is $6.25 \mu \mathrm{g} / \mathrm{ml}$. Also, the concentration that was needed to kill the bacteria is $12.5 \mu \mathrm{g} / \mathrm{ml}$. However, the 


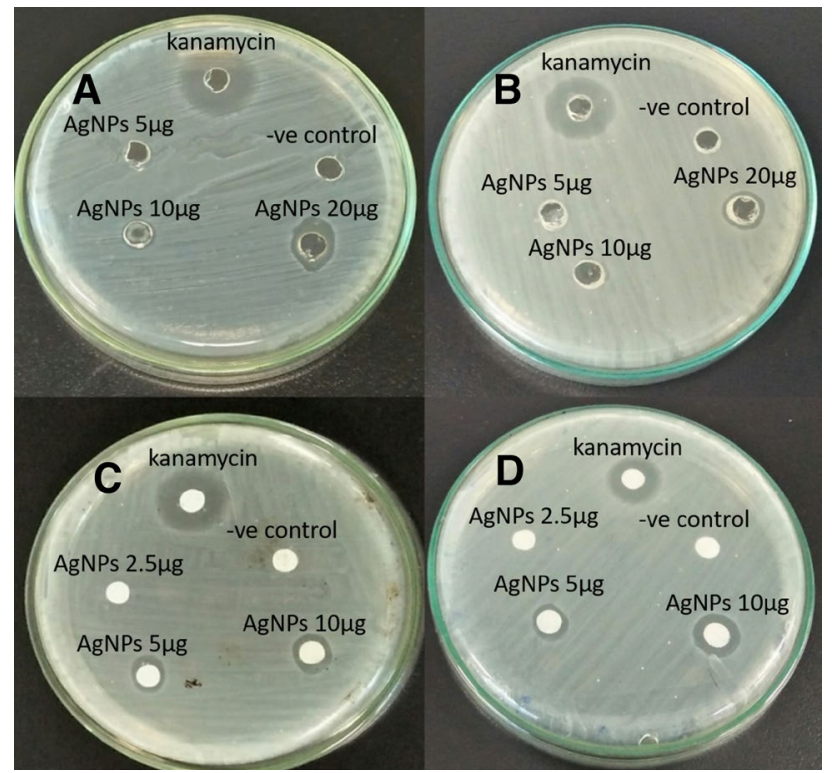

Fig. 4 Illustrates well diffusion of AgNPs capping with Ocimum basilicum L. (A), and Hibiscus sabdariffa L. extract (B), and the disc diffusion of AgNPs capping with Ocimum basilicum L. (C) and Hibiscus sabdariffa L. extract (D)

values of both MIC and MBC were equal to $1.56 \mu \mathrm{g} / \mathrm{ml}$ of AgNPs combined with phage ZCSE6 against $S$. enterica bacteria. The clearance was observed in these wells 50 , $25,12.5$, and $6.25 \mu \mathrm{g} / \mathrm{ml}$ containing AgNPs capped with each of Ocimum basilicum L. and Hibiscus sabdariffa L. extracts indicating the inhibition of bacterial growth. Whereas with concentrations of $3.1,1.5$, and $0.75 \mu \mathrm{g} / \mathrm{ml}$, turbidity was seen, exhibiting the growth of bacteria. The suspensions from the wells of 50, 25, 12.5, and $6.25 \mu \mathrm{g} / \mathrm{ml}$ were streaked on TSA agar plates and incubated for $24 \mathrm{~h}$ at $37^{\circ} \mathrm{C}$, resulting in no growth of bacteria in the first three concentrations which confirmed their bactericidal agent.
In the case of AgNPs combined with phage, the synergetic effect has significantly appeared as the clearance was seen at $50,25,12.5,6.25,3.1$, and $1.5 \mu \mathrm{g} / \mathrm{ml}$, and all of them were unable to grow on the TSA plates. However, the phage alone was not able to show MIC or MBC.

\subsubsection{Time-Killing Curve}

The time-killing curves results showed the significant difference between using pure phage ZCSE6 and a combination of it with the two biosynthesized AgNPs (Fig. 7). The data indicated that the pure phage ZCSE6 at MOI 0.1 was able to reduce the bacterial intensity during the first $360 \mathrm{~min}$. After that, the bacteria developed a resistance to the phage. However, the different concentrations of pure AgNPs coated with Ocimum basilicum L. $3 \mu \mathrm{g} / \mathrm{ml}$ and $6 \mu \mathrm{g} / \mathrm{ml}$ reduced the bacterial growth to 0.21 and 0.13 $\mathrm{OD}_{600}$ after $360 \mathrm{~min}$ of the experiment. Then the growth increased in case of $3 \mu \mathrm{g} / \mathrm{ml}$ to reach $0.51 \mathrm{OD}_{600}$ at the end of the experiment. On the other hand, the combination of phage ZCSE6 at MOI 0.1 and AgNPs coated with Ocimum basilicum L. at $3 \mu \mathrm{g} / \mathrm{ml}$ exhibited a reduction to $0.1 \mathrm{OD}_{600}$ after $660 \mathrm{~min}$ of the experiment (Fig. 7A). While, as shown in Fig. 7B, the different concentrations of pure AgNPs coated with Hibiscus sabdariffa L. at $6 \mu \mathrm{g} / \mathrm{ml}$ reduced the bacterial growth to $0.31 \mathrm{OD}_{600}$ after $600 \mathrm{~min}$. However, in the concentration of $3 \mu \mathrm{g} / \mathrm{ml}$, the bacteria growth became $1.4 \mathrm{OD}_{600}$ after $600 \mathrm{~min}$. The combination of phage ZCSE6 at MOI 0.1 and AgNPs coating with Hibiscus sabdariffa $\mathrm{L}$. at $3 \mu \mathrm{g} / \mathrm{ml}$ exhibited a reduction to $0.3 \mathrm{OD}_{600}$ at $600 \mathrm{~min}$ of the experiment. The pure phage ZCSE6 showed the bactericidal but do not last for a long time. However, the phage ZCSE6 at MOI of 0.1 with AgNPs $3 \mu \mathrm{g} / \mathrm{ml}$ exhibited a highly significant inhibitory effect.
Table 1 Inhibitory zones obtained from direct spotting, disc, and well diffusion test

\begin{tabular}{lllll}
\hline & Diameter $(\mathrm{mm})$ & & & \\
\cline { 2 - 5 } & Serial dilution & Direct spotting $(10 \mu \mathrm{l})$ & $\begin{array}{l}\text { Disc diffusion } \\
(10 \mu \mathrm{l})\end{array}$ & $\begin{array}{l}\text { Well dif- } \\
\text { fusion }(20 \\
\mu \mathrm{l})\end{array}$ \\
\hline AgNPs $^{\mathrm{a}}$ & & & 20.1 \\
& + ve control (Kanamycin) & Antibacterial effect & 18 & 0 \\
& - ve control & No effect & 0 & 11.6 \\
& $50 \mu \mathrm{g} / \mathrm{ml} \mathrm{AgNPs}$ & Antibacterial effect & 9.8 & 10.5 \\
AgNPs $^{\text {b }}$ & $100 \mu \mathrm{g} / \mathrm{ml} \mathrm{AgNPs}$ & Antibacterial effect & 10.1 & 18.1 \\
& $+\mathrm{ve}$ control (Kanamycin) & Antibacterial effect & 14.7 & 0 \\
& $-\mathrm{ve}$ control & No effect & 0 & 8 \\
& $50 \mu \mathrm{g} / \mathrm{ml} \mathrm{AgNPs}$ & Antibacterial effect & 9.1 & 10.5 \\
\hline
\end{tabular}

$\mathrm{AgNPs}^{\mathrm{a}}$ : AgNPs capping with Ocimum basilicum $\mathrm{L}$.

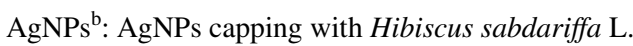




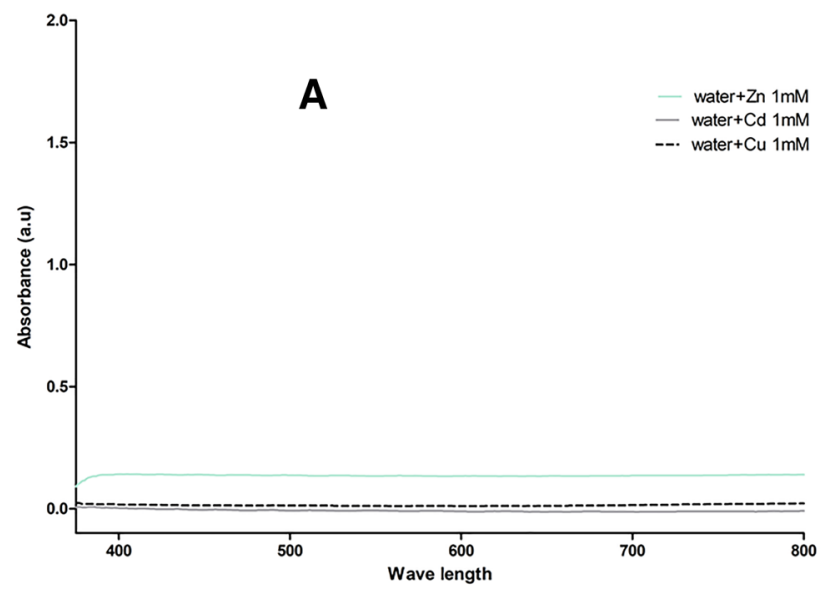



Fig. 5 UV-Vis spectra of AgNPs with the heavy metal. The heavy metal with water had no UV-Vis spectra (A). The AgNPs $s_{1}$ were capped with Ocimum basilicum L. B At different concentrations of

\subsubsection{Phage ZCSE6 and AgNPs Application in Milk}

After $24 \mathrm{~h}$ of incubation, In the case of phage with the bacteria, there was no significant reduction in the bacterial growth. However, the $3 \mu \mathrm{g} / \mathrm{ml} \mathrm{AgNPs}$ and $3 \mu \mathrm{g} / \mathrm{ml}$ of the same AgNPs combined with phage showed $70 \%$ and more than $99.9 \%$ bacterial reduction effect. The results were similar in both types of prepared AgNPs (Fig. 8).

The coagulation was monitored and the $\mathrm{pH}$ was determined after 7 days of incubation at $25{ }^{\circ} \mathrm{C}$. The $\mathrm{pH}$ of the negative and positive controls was 4.5 , whereas the $\mathrm{pH}$ of AgNPs combined with phage ZCSE6 was 5, and they were all coagulated. The effect of nanoparticles differed through the samples as the following: The highest $\mathrm{pH}$ level was observed at 6.7 and 6.1 with the treatment of $6.2 \mu \mathrm{g} / \mathrm{ml}$ AgNPs capped with Ocimum basilicum L., and Hibiscus sabdariffa L., respectively, and no coagulation was observed (Fig. 9). The $3 \mu \mathrm{g} / \mathrm{ml} \mathrm{AgNPs} \mathrm{treatment} \mathrm{showed} \mathrm{different}$ behavior between the two coating materials as the coating of

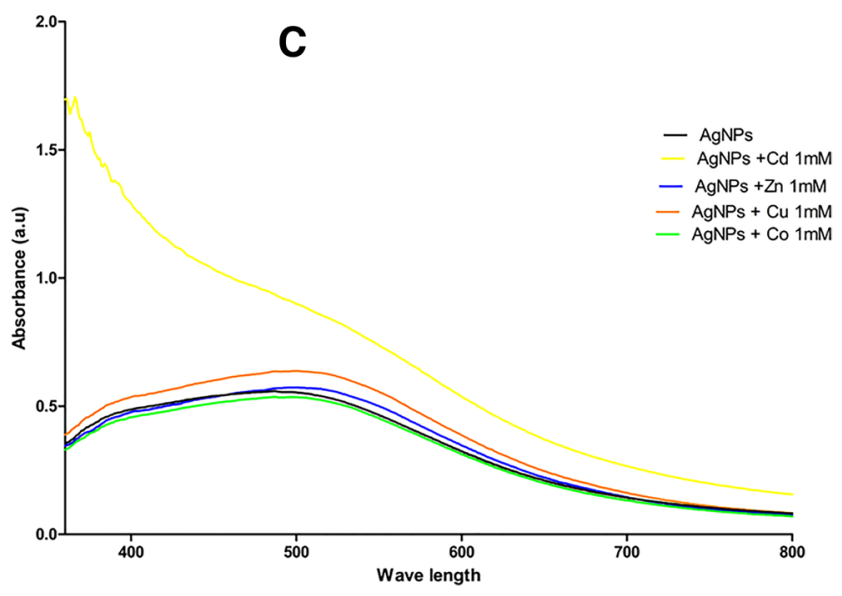

heavy metals $(0.1$ and $1 \mathrm{mM}) . \mathrm{AgNPs}_{2}$ capped with Hibiscus sabdariffa $\mathrm{L}$. C at $1 \mathrm{mM}$ concentration of various heavy metals

the AgNPs with Hibiscus sabdariffa L. exhibited $\mathrm{pH}$ at 5.3 and the milk was partially coagulated, while using $3 \mu \mathrm{g} / \mathrm{ml}$ of AgNPs with Ocimum basilicum alone or in combination with phage showed no coagulation and the $\mathrm{pH}$ was 6 (Fig. 9).

While AgNPs with Ocimum basilicum L. gave a pH of 6 as the treatment with $3 \mu \mathrm{g} / \mathrm{ml}$ nanoparticles and phage which were about $\mathrm{pH} 6$, resulting in no coagulation.

\section{Discussion}

Antimicrobial resistance has been identified as one of the three major problems countered in human health by the World Health Organization (WHO). This problem has emerged globally due to indiscriminate and extensive use of antibiotics. The development of new and effective antimicrobials against infections caused by antibiotic-resistant bacteria has been increasingly interesting [28]. Nanoparticles have a wide range of applications due to their smaller 




Fig. 6 Shows phage stability after the incubation for $48 \mathrm{~h}$ of with Ocimum basilicum L. (AgNPs 1 ) and Hibiscus sabdariffa L. $\left(\mathrm{AgNPs}_{2}\right)$ extracts and phage ZCSE6

size and higher surface area to volume ratio and they are now being studied extensively for their antibacterial and antibiofilm effects [29, 30]. AgNPs coupled with natural products such as Ocimum basilicum L. and Hibiscus sabdariffa L. extracts decrease the bacterial resistance occurrence rate. Also, to decrease AgNPs toxicity because it affects the environment and public health decreasing their concentration is suggested [16, 31, 32]. According to the literature, Anthocyanins are a group of compounds including cyanidin based $p$-coumaryl and malonyl acids; cyanidin based $p$-coumaryl acid; cyanidin based $p$-coumaryl acid; peonidin 3-( $p$-coumaryl glucoside)-5-glucoside; cyanidin based $p$-coumaryl and malonyl acids. Anthocyanins, which are abundant in both plants extracts could be the main source for functionalizing AgNPs [16, 33, 34].

In our study, we hypothesize the possible synergistic effect between the isolated phage ZCSE6 and AgNPs. The new approach will give insights into the interaction of ZCSE6 and AgNPs nanoparticles while qualifying as a potential infection treatment and bio-control agent in the different scientific aspects. Based on the recent research findings, there is still a gap in understanding the mechanistic pattern of combining the phages and nanoparticles and whether the synergy between them can help out power the limitations each of them had.

To create AgNPs effectively, the $\mathrm{Ag}^{+}$ions were bioreduced utilizing the Ocimum basilicum L. and Hibiscus sabdariffa L. extracts as a bio-reducing agent in this study. AgNPs formation has also been confirmed by the measurement of SPR in the resultant nanoparticles. The Ocimum basilicum L. extract was shown to have a variety of phytochemical components (rosmarinic acid and caffeic acid) be the reason behind the bio-reduction of the $\mathrm{Ag}^{+}$ions and the capping with the formed AgNPs $[35,36]$. The absorption of AgNPs depends on the particle size, dielectric medium, and


Fig. 7 Illustrates the Time-Killing curve of S. enterica, AgNPs ${ }^{1}$ capped with Ocimum basilicum L. and ZCSE6 phage (A), the Time-Killing curve of S. enterica, AgNPs ${ }^{2}$ capped with Hibiscus sabdariffa L. extract, and phage ZCSE6 (B) 




Fig. 8 Synergistic effect of phage ZCSE6 and AgNPs coated with Ocimum basilicum L. and Hibiscus sabdariffa L.

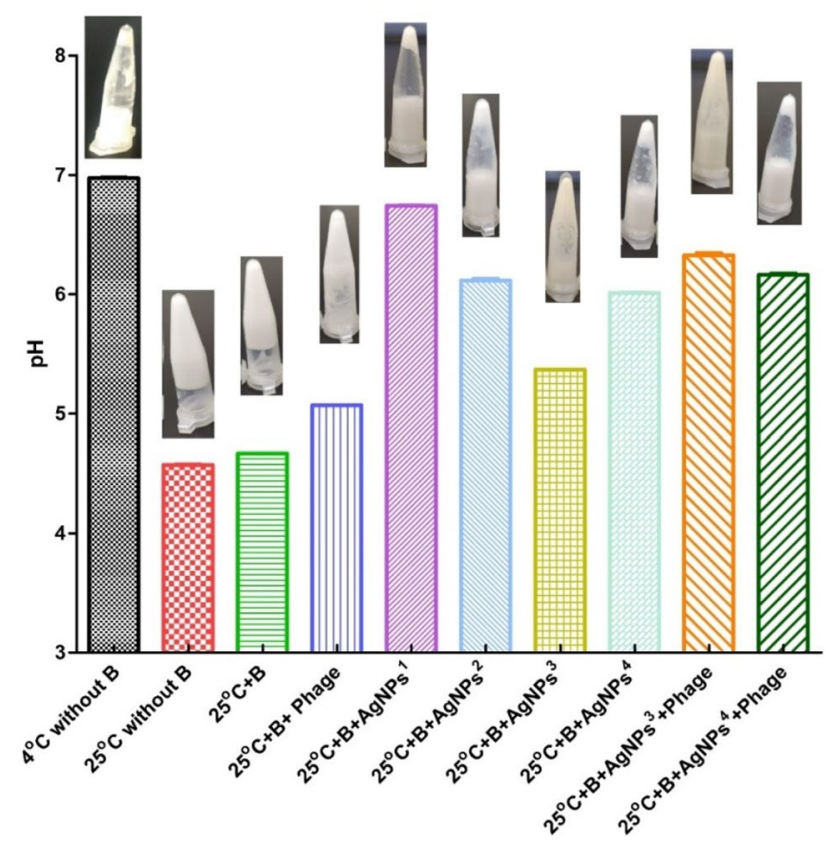

Fig. 9 Illustrates the effect of phage ZCSE6 and $\mathrm{AgNPs}^{1}$ (Ocimum basilicum L.; $6 \mu \mathrm{g} / \mathrm{ml}$ ), AgNPs $^{2}$ (Hibiscus sabdariffa L. $6 \mu \mathrm{g} / \mathrm{ml}$ ), $\mathrm{AgNPs}^{3}$ (Ocimum basilicum L.; $3 \mu \mathrm{g} / \mathrm{ml}$ ), and $\mathrm{AgNPs}^{4}$ (Ocimum basilicum $\mathrm{L} . ; 3 \mu \mathrm{g} / \mathrm{ml}$ ) on the $\mathrm{pH}$ and milk coagulation

chemical surroundings. TEM is an important technique for the characterization of nanomaterials, used to obtain quantitative measures of particle size, size distribution, and morphology. The magnification of TEM is mainly determined by the ratio of the distance between the objective lens and the specimen and the distance between the objective lens and its image plane. According to the TEM images after 4 months from the biosynthesis, the AgNPs had the same shape and smaller sizes (Supplementary data, Fig. S3). This data is compatible with previous studies in shape which means a higher level of stability [37].

The nanoparticles are characterized by having a highly developed surface and particles with small sizes that increase their antimicrobial effect [38]. AgNPs can enter the microbial cell and interact with its cellular structures and different biochemicals such as DNA, proteins, and lipids. Thus, it can induce damage to the protein [39]. In our study, the green synthesized AgNPs have shown their effectiveness in killing bacteria and eradicating biofilms (supplementary data, Fig. S1) more efficiently than previous studies [40]. The nanoparticles, depending on their surface chemistry, charge, and hydrophobicity, interact with lipids, LPS, or proteins of the bacterial cell membrane [41]. Subsequently, depending on this interaction, the nanoparticles gain entry into the biofilm. The penetration of nanoparticles depends on many factors such as biofilm maturity, biofilm surface composition and chemistry, nanoparticle size, surface charge, surface chemistry, and nanoparticle concentration [42-44]. Hence, the antimicrobial action of AgNPs relies on disrupting several biofilm and bacterial components. The interactions involved in approaching the biofilm surface, penetration, and internal migration interact with biofilm components and cellular components. Also, other nanoparticals can be used for antibacterial applications such as the biosynthesis of spinel nickel ferrite nanowhiskers and their biomedical applications. To tackle this challenge, ecologically friendly nanostructure fabrication technologies must be discovered. Plant extracts are used to generate green nanostructure synthesis, also operate as natural reducing and stabilizing agents for the formation of nanostructures, moreover, has low toxicity and eco-friendliness. Metallic nanoparticles (NPs) (silver, gold, zinc, etc.) are one form of nanomaterial that can be utilized directly as an antibacterial agent or as or as a nanocarrier for delivering and targeting antibiotics to E. coli. There are various types such as polymeric NPs, lipidic nanocarriers, metallic nanocarriers, nanomicelles, nanoemulsion/nanosuspension, dendrimers, graphene, etc. While the Ceramic nanostructures have distinct morphologies, have appealing properties and a wide range of biomedical and medical applications [45-47].

Our study showed the synergistic effect of both phage ZCSE6 and AgNPs to inhibit the growth of S. enterica. Interestingly, to promote the natural product-based synthesis and applications of nanoparticles, the synergetic combination was focused on using the phage rather than any commercial antibiotics used against the organisms. Many synergetic applications of the AgNPs, along with current 
commercial antibiotics with different concentrations, show more antibacterial activities [48]. According to Ahiwale et al., [49] the synergistic effect between gold nanoparticles (AgNPs) and C3 tailed phage from the Podoviridae family showed activity against MDR Pseudomonas aeruginosa biofilm.

Furthermore, this study was aimed at determining the MIC and MBC of AgNPs against S. enterica. The antibacterial effects of nanoparticles are routinely assessed by MIC test. Serial dilutions of a solution are used for MIC to determine the lowest concentration of material that would still show antibacterial properties. The antimicrobial effects of AgNPs are mostly attributed to silver ions [50]. AgNPs continuously release silver ions in an aqueous microenvironment [51]. Because of the bigger surface area of silver nanoparticles, they show a stronger and better bactericidal effect. Also, The MBC was defined as the lowest concentration of the antibacterial agents that completely kill the bacteria. Based on this in vitro study, phage ZCSE6 in combination with AgNPs with a concentration less than MIC suppresses the regrowth of $S$. enterica bacteria $24 \mathrm{~h}$ post-treatment. The same concept was achieved when the phage PEV20 was combined with ciprofloxacin [52].

Time-kill curves that monitor bacterial growth and death over a wide range of antimicrobial concentrations have been frequently used to evaluate the effect of antimicrobials over time. In our study, there is a significant inhibitory effect when phage ZCSE6 is combined with AgNPs in comparison to using pure AgNPs with the same concentration of the phage with the same MOI alone. Based on the results, the tested bacteria were dead in a shorter time at a low concentration of AgNPs with phage. This may be due to the cell wall structure of Gram-negative bacteria and the different mechanisms of action for the phage and AgNPs. In addition to the continued stress on the bacteria by the AgNPs with a concentration lower than MIC that reduced the ability of bacteria to develop resistance against the phage. Further experiments are needed to explore the mechanism of PhageNano Synergy (PNS).

The presence of $\mathrm{Cd}^{2+}$ in water, soil, and plants has been studied for decades because of its toxicity [53, 54]. The Colorimetric properties of green synthesized AgNPs have been studied to confirm the presence of heavy metals such as zinc, copper, mercury, and lead $[55,56]$. The sensing activity of AgNPs biosynthesized with natural products such as Ocimum basilicum L. and Hibiscus sabdariffa L. extracts as $\mathrm{Cd}$ sensor were shown in Fig. 5. When the basic concentration of $\mathrm{Cd}^{2+}$ ions $(1 \mathrm{mM})$ in an aqueous solution was added to AgNPs, the magnitudes of the absorption peaks were observed in the maximum at $370 \mathrm{~nm}$. Whereas there is no change of peak strength was observed when other heavy metal was used with the same concentration. Thus, those AgNPs in this study are highly specific for the presence of
$\mathrm{Cd}^{2+}$ in the aqueous solution (Supplementary data, Fig. S2). The selectivity of preparing AgNPs sensitive with $\mathrm{Cd}^{2+}$ is achieved in previous work [57].

Dairy products can get contaminated at different stages along the production chain. Although pasteurization kills most of the dangerous microorganisms present in milk, the contamination could happen due to inappropriate pasteurization or post-pasteurization $[58,59]$. As a result, using safe and efficient antimicrobial agents is important for public health. The results of the milk experiments decided with the time-killing curve. The curve showed that four hours were suitable for the phage to kill the bacteria without showing secondary growth. While after $24 \mathrm{~h}$, the bacteria evolved resistance against the phage as described before [60] and confirmed in the milk experiment (Fig. 8). According to the AgNPs concentration, $3 \mu \mathrm{g} / \mathrm{ml}$ was below the MIC and did not show a low antibacterial effect, so it was used to mimic the adverse effect of using AgNPs and study the synergetic effect with phage. The combination of phage and $3 \mu \mathrm{g} / \mathrm{ml}$ AgNPs showed a significant reduction in bacterial growth as exhibited in Fig. 8 which agreed with the time-killing curve. Many studies used biosynthesized AgNPs in milk to detect antibiotics [61], melamine [62], and lysozyme protein [63]. Here, these results showed a promising future for combination therapy of phage and nanoparticles as an alternative to antibiotics in the biocontrol of dairy products. However, further studies should be conducted to address the cytotoxicity and other physicochemical properties of the milk.

According to Kauzmann [64], the solubility of caseins decreases by lowering $\mathrm{pH}$, leading to coagulation as the result of disturbance of the internal structure and external surface layers of the casein micelles. Consequently, the net charge of caseins was decreased and causes the solubilization of colloidal calcium phosphate from the micelles into the solution since it is well known that at a $\mathrm{pH}$ of 5.1, calcium is almost completely removed from the micelle. Further lowering the $\mathrm{pH}$ to the isoelectric $\mathrm{pH}$ (around $\mathrm{pH}$ 4.6), the casein curdles because the beta-casein which is positively charged acts as a center for aggregation with the alpha-s1-casein framework which is still negatively charged, eventually the milk starts to gel [65]. Lowering the $\mathrm{pH}$ of the milk occurs naturally by lactic acid bacteria that convert lactose to lactic acid through fermentation, causing the milk to curdle followed by spoilage. Some studies tried to figure out the exact mechanism of milk curdling and the effect of $\mathrm{pH}$ on it $[65,66]$. They showed that lowering $\mathrm{pH}$ caused the milk to curdle and form a gel, leading to spoilage which agreed with our results. Based on our results, the phage did not show any effect on the milk curdling as it was not specific for lactic acid bacteria, unlike the nanoparticles. Our results revealed that AgNPs cause no curdling as they have a significant inhibitory effect against lactic acid bacteria which agreed with some studies which figured out 
that nanoparticles have an antibacterial effect against Grampositive bacteria, including (S. aureus, B. cereus, L. casei, $L$. bulgaricus, L. acidophilus, and L. lactis) [67]. The results indicate that using Ocimum basilicum L. and Hibiscus sabdariffa L. natural products to biosynthesis AgNPs have a stabilizing effect, which enhances its use as an antibacterial agent opens the gate for future research regarding the use of phage-nanoparticles in the food sector and therapeutics.

\section{Conclusion}

In this study, a new approach of coupling the AgNPs with natural products (Ocimum basilicum L. and Hibiscus sabdariffa L.) was explored to increase their antibacterial abilities and cause synergism between them to reach higher infection control. The natural products were prepared and the biosynthesized AgNPs were characterized thoroughly by UV-Vis spectroscopy, TEM, and SEM. To evaluate the antibacterial effect of the coupled AgNPs against $S$. enterica, MIC, MBC, in vitro time-kill assay, well diffusion, and direct spotting were tested. Moreover, the stability of the AgNPs was assessed. The experiments showed that the prepared AgNPs are polydisperse, and the novel AgNPs have an effective bactericidal activity and that there is a strong synergistic effect between phage ZCSE6 and 3\% AgNPs which prevent the secondary infection that occurred in the bacteria. In conclusion, this study showed the antimicrobial of biosynthesized AgNPs and their combination with phage ZCSE6 to control S. enterica and has a strong potential as an alternative to antibiotics.

Supplementary Information The online version contains supplementary material available at https://doi.org/10.1007/s10904-022-02234-y.

Acknowledgements We would like to thank Amera Elsayed, Anan Safwat, Salsabil Makky, Rana Nofal, and Mohamed Shokry for their kind help and support.

Funding Open access funding provided by The Science, Technology \& Innovation Funding Authority (STDF) in cooperation with The Egyptian Knowledge Bank (EKB). This research was funded by the Egyptian Sciences and Technology Development Fund (STDF), grant \#41909.

Open Access This article is licensed under a Creative Commons Attribution 4.0 International License, which permits use, sharing, adaptation, distribution and reproduction in any medium or format, as long as you give appropriate credit to the original author(s) and the source, provide a link to the Creative Commons licence, and indicate if changes were made. The images or other third party material in this article are included in the article's Creative Commons licence, unless indicated otherwise in a credit line to the material. If material is not included in the article's Creative Commons licence and your intended use is not permitted by statutory regulation or exceeds the permitted use, you will need to obtain permission directly from the copyright holder. To view a copy of this licence, visit http://creativecommons.org/licenses/by/4.0/.

\section{References}

1. H. Ochman, E.A. Groisman, The origin and evolution of species differences in Escherichia coli and Salmonella typhimurium. Mol. Ecol. Evol. Approaches Appl. 479-493 (1994)

2. V.J. Cirillo, Fever and reform: the typhoid epidemic in the Spanish-American War. J. Hist. Med. Allied Sci. 55, 363-397 (2000)

3. M.A. Gordon, Salmonella infections in immunocompromised adults. J. Infect. 56, 413-422 (2008)

4. R.K. Gast, R.E. Porter Jr., Salmonella infections. Dis. Poult. 717$753(2020)$

5. S.B. Levy, B. Marshall, Antibacterial resistance worldwide: causes, challenges and responses. Nat. Med. 10, S122-S129 (2004)

6. J.Y. Hyeon, J.W. Chon, I.G. Hwang, H.S. Kwak, M.S. Kim, S.K. Kim, I.S. Choi, C.S. Song, C. Park, K.H. Seo, Prevalence, antibiotic resistance, and molecular characterization of Salmonella serovars in retail meat products. J. Food Prot. 74, 161-166 (2011). https://doi.org/10.4315/0362-028X.JFP-10-327

7. A.S. Nilsson, Phage therapy-constraints and possibilities. Ups. J. Med. Sci. (2014). https://doi.org/10.3109/03009734.2014. 902878

8. A. Mohamed, O. Taha, H.M. El-Sherif, P.L. Connerton, S.P.T. Hooton, N.D. Bassim, I.F. Connerton, A. El-Shibiny, Bacteriophage ZCSE2 is a potent antimicrobial against Salmonella enterica Serovars: ultrastructure, genomics and efficacy. Viruses. (2020). https://doi.org/10.3390/v12040424

9. A. Górski, R. Międzybrodzki, G. Węgrzyn, E. Jończyk-Matysiak, J. Borysowski, B. Weber-Dąbrowska, Phage therapy: current status and perspectives. Med. Res. Rev. 40, 459-463 (2020)

10. A. El-Shibiny, S. El-Sahhar, Bacteriophages: the possible solution to treat infections caused by pathogenic bacteria. Can. J. Microbiol. (2017). https://doi.org/10.1139/cjm-2017-0030

11. M.S. Fayez, T.A. Hakim, M.M. Agwa, M. Abdelmoteleb, R.G. Aly, N.N. Montaser, A.S. Abdelsattar, N. Rezk, A. El-Shibiny, Topically applied bacteriophage to control multi-drug resistant klebsiella pneumoniae infected wound in a rat model. Antibiotics. 10, 1048 (2021)

12. A. Hamad, K.S. Khashan, A. Hadi, Silver nanoparticles and silver ions as potential antibacterial agents. J. Inorg. Organomet. Polym. Mater. 1-18 (2020)

13. C. Losasso, S. Belluco, V. Cibin, P. Zavagnin, I. Mičetić, F. Gallocchio, M. Zanella, L. Bregoli, G. Biancotto, A. Ricci, Antibacterial activity of silver nanoparticles: sensitivity of different Salmonella serovars. Front. Microbiol. 5, 227 (2014)

14. M.M. Farouk, A. El-Molla, F.A. Salib, Y.A. Soliman, M. Shaalan, The role of silver nanoparticles in a treatment approach for multidrug-resistant Salmonella species isolates. Int. J. Nanomed. 15, 6993 (2020)

15. S. Prabhu, E.K. Poulose, Silver nanoparticles: mechanism of antimicrobial action, synthesis, medical applications, and toxicity effects. Int. Nano Lett. 2, 1-10 (2012)

16. N.K. Kalita, J.N. Ganguli, Hibiscus sabdariffa L. leaf extract mediated green synthesis of silver nanoparticles and its use in catalytic reduction of 4-nitrophenol, Inorg. Nano-Metal Chem. 47, 788-793 (2017)

17. S. Wacharanad, P. Thatree, P. Yiemwattana, P. Paoprajak, P. Ngamsangiam, M. Valyanont, I. Yiemwattana, Antimicrobial activity of roselle-capped silver nanochip on aggregatibacter actinomycetemcomitans. Eur. J. Dent. (2021)

18. X.-F. Zhang, Z.-G. Liu, W. Shen, S. Gurunathan, Silver nanoparticles: synthesis, characterization, properties, applications, and therapeutic approaches. Int. J. Mol. Sci. 17, 1534 (2016)

19. F. Fathiazad, A. Matlobi, A. Khorrami, S. Hamedeyazdan, H. Soraya, M. Hammami, N. Maleki-Dizaji, A. Garjani, 
Phytochemical screening and evaluation of cardioprotective activity of ethanolic extract of Ocimum basilicum L. (basil) against isoproterenol induced myocardial infarction in rats. DARU J. Pharm. Sci. 20, 1-10 (2012)

20. O. Carvajal-Zarrabal, S.M. Waliszewski, D.M. Barradas-Dermitz, Z. Orta-Flores, P.M. Hayward-Jones, C. Nolasco-Hipólito, O. Angulo-Guerrero, R. Sánchez-Ricaño, R.M. Infanzón, P.R.L. Trujillo, The consumption of Hibiscus sabdariffa dried calyx ethanolic extract reduced lipid profile in rats. Plant Foods Hum. Nutr. 60, 153-159 (2005)

21. R.K. Maeah, B.A.A.-H. Hasoon, A.I. Abd-Alwahab, K.F.F. AlAzawi, W.B.A. Hameedi, Biosynthesis of silver nanoparticles using Hibiscus sabdariffa and their biological application. Eur. Asian J. Biosci. 14, 3377-3383 (2020)

22. M. Jafir, J.N. Ahmad, M.J. Arif, S. Ali, S.J.N. Ahmad, Characterization of Ocimum basilicum synthesized silver nanoparticles and its relative toxicity to some insecticides against tobacco cutworm, Spodoptera litura Feb.(Lepidoptera; Noctuidae). Ecotoxicol. Environ. Saf. 218, 112278 (2021)

23. A. Ramadan, G. Soliman, S.S. Mahmoud, S.M. Nofal, R.F. AbdelRahman, Evaluation of the safety and antioxidant activities of Crocus sativus and Propolis ethanolic extracts. J. Saudi Chem. Soc. 16, 13-21 (2012)

24. B. Ajitha, Y.A.K. Reddy, S. Shameer, K.M. Rajesh, Y. Suneetha, P.S. Reddy, Lantana camara leaf extract mediated silver nanoparticles: antibacterial, green catalyst. J. Photochem. Photobiol. B Biol. 149, 84-92 (2015)

25. W. Gao, J. Wu, J. Wei, L. Pu, C. Guo, J. Yang, M. Yang, H. Luo, Brazilian green propolis improves immune function in aged mice. J. Clin. Biochem. Nutr. 55, 7-10 (2014)

26. P. Parvekar, J. Palaskar, S. Metgud, R. Maria, S. Dutta, The minimum inhibitory concentration (MIC) and minimum bactericidal concentration (MBC) of silver nanoparticles against Staphylococcus aureus. Biomater. Investig. Dent. 7, 105-109 (2020)

27. Y.Y. Loo, Y. Rukayadi, M.-A.-R. Nor-Khaizura, C.H. Kuan, B.W. Chieng, M. Nishibuchi, S. Radu, In vitro antimicrobial activity of green synthesized silver nanoparticles against selected gramnegative foodborne pathogens. Front. Microbiol. 9, 1555 (2018)

28. S.R. Shrivastava, P.S. Shrivastava, J. Ramasamy, World health organization releases global priority list of antibiotic-resistant bacteria to guide research, discovery, and development of new antibiotics. J. Med. Soc. 32, 76 (2018)

29. C.G.A. Das, V.G. Kumar, T.S. Dhas, V. Karthick, K. Govindaraju, J.M. Joselin, J. Baalamurugan, Antibacterial activity of silver nanoparticles (biosynthesis): a short review on recent advances. Biocatal. Agric. Biotechnol. 27, 101593 (2020)

30. C. Rodríguez-Serrano, J. Guzmán-Moreno, C. Ángeles-Chávez, V. Rodríguez-González, J.J. Ortega-Sigala, R.M. Ramírez-Santoyo, L.E. Vidales-Rodríguez, Biosynthesis of silver nanoparticles by Fusarium scirpi and its potential as antimicrobial agent against uropathogenic Escherichia coli biofilms. PLoS ONE 15, e0230275 (2020)

31. B.A. Omran, H.N. Nassar, N.A. Fatthallah, A. Hamdy, E.H. ElShatoury, N.S. El-Gendy, Characterization and antimicrobial activity of silver nanoparticles mycosynthesized by Aspergillus brasiliensis. J. Appl. Microbiol. 125, 370-382 (2018)

32. H.H. Latif, M. Ghareib, M.A. Tahon, Phytosynthesis of silver nanoparticles using leaf extracts from Ocimum basilicum and Mangifira indica and their effect on some biochemical attributes of Triticum aestivum. Gesunde Pflanz 69, 39-46 (2017)

33. A.C. Pedro, F. Moreira, D. Granato, N.D. Rosso, Extraction of bioactive compounds and free radical scavenging activity of purple basil (Ocimum basilicum L.) leaf extracts as affected by temperature and time. An. Acad. Bras. Cienc. 88, 1055-1068 (2016)
34. S.A. Al-Thabaiti, Z. Khan, Biogenic synthesis of silver nanoparticles, sensing and photo catalytic activities for bromothymol blue. J. Photochem. Photobiol. 3, 100010 (2020)

35. S. Rubab, S. Bahadur, U. Hanif, A.I. Durrani, A. Sadiqa, S. Shafique, U. Zafar, M. Shuaib, Z. Urooj, M.M. Nizamani, Phytochemical and antimicrobial investigation of methanolic extract/ fraction of Ocimum basilicum L. Biocatal. Agric. Biotechnol. 31, 101894 (2021)

36. L. Muthulakshmi, T. Vijayakumar, P. Selvam, J. Annaraj, S. Ranjan, N. Dasgupta, Strong and nonspecific synergistic antibacterial/ antibiofilm impact of nano-silver biosynthesized and decorated with active ingredients of Oscimum basilicum L. 3 Biotech. 11, $1-12(2021)$

37. O. Velgosova, E. Čižmárová, J. Málek, J. Kavuličova, Effect of storage conditions on long-term stability of Ag nanoparticles formed via green synthesis. Int. J. Miner. Metall. Mater. 24, 1177-1182 (2017)

38. A. Kędziora, M. Speruda, E. Krzyżewska, J. Rybka, A. Łukowiak, G. Bugla-Płoskońska, Similarities and differences between silver ions and silver in nanoforms as antibacterial agents. Int. J. Mol. Sci. 19, 444 (2018)

39. A.S. Abdelsattar, R. Nofal, S. Makky, A. Safwat, A. Taha, A. ElShibiny, The synergistic effect of biosynthesized silver nanoparticles and phage ZCSE2 as a novel approach to combat multidrugresistant Salmonella enterica. Antibiotics. (2021). https://doi.org/ 10.3390/antibiotics10060678

40. T. Dutta, A.P. Chattopadhyay, M. Mandal, N.N. Ghosh, V. Mandal, M. Das, Facile green synthesis of silver bionanocomposite with size dependent antibacterial and synergistic effects: a combined experimental and theoretical studies. J. Inorg. Organomet. Polym Mater. 30, 1839-1851 (2020)

41. D.P. Linklater, V.A. Baulin, X. Le Guével, J. Fleury, E. Hanssen, T.H.P. Nguyen, S. Juodkazis, G. Bryant, R.J. Crawford, P. Stoodley, Antibacterial action of nanoparticles by lethal stretching of bacterial cell membranes. Adv. Mater. 32, 2005679 (2020)

42. L.E. A. Chávez de Paz, K.A. Resin, D.S. Howard, P.L. Sutherland, Wejse, Antimicrobial effect of chitosan nanoparticles on Streptococcus mutans biofilms, Appl. Environ. Microbiol. 77, 3892-3895 (2011)

43. T.-O. Peulen, K.J. Wilkinson, Diffusion of nanoparticles in a biofilm. Environ. Sci. Technol. 45, 3367-3373 (2011)

44. D.S.W. Benoit, K.R. Sims Jr, D. Fraser, Nanoparticles for oral biofilm treatments. ACS Nano. 13, 4869-4875 (2019)

45. H.Q. Alijani, S. Iravani, S. Pourseyedi, M. Torkzadeh-Mahani, M. Barani, M. Khatami, Biosynthesis of spinel nickel ferrite nanowhiskers and their biomedical applications. Sci. Rep. 11, 1-7 (2021)

46. M. Barani, M. Zeeshan, D. Kalantar-Neyestanaki, M.A. Farooq, A. Rahdar, N.K. Jha, S. Sargazi, P.K. Gupta, V.K. Thakur, Nanomaterials in the management of gram-negative bacterial infections. Nanomaterials. 11, 2535 (2021)

47. Y. Cao, M. Abbasi, H.Q. Alijani, M.R. Akbarizadeh, S. Iravani, M. Barani, K. Najafi, S. Khatami, M. Khatami, Ceramic magnetic ferrite nanoribbons: eco-friendly synthesis and their antifungal and parasiticidal activity. Ceram. Int. (2021)

48. W.R. Rolim, C. Lamilla, J.C. Pieretti, M. Díaz, G.R. Tortella, M.C. Diez, L. Barrientos, A.B. Seabra, O. Rubilar, Comparison of antibacterial and antibiofilm activities of biologically synthesized silver nanoparticles against several bacterial strains of medical interest. Energy Ecol. Environ. 4, 143-159 (2019)

49. S.S. Ahiwale, A.V. Bankar, S. Tagunde, B.P. Kapadnis, A bacteriophage mediated gold nanoparticles synthesis and their antibiofilm activity. Indian J. Microbiol. 57, 188-194 (2017). https:// doi.org/10.1007/s12088-017-0640-x 
50. Y. Matsumura, K. Yoshikata, S. Kunisaki, T. Tsuchido, Mode of bactericidal action of silver zeolite and its comparison with that of silver nitrate. Appl. Environ. Microbiol. 69, 4278-4281 (2003)

51. C.-N. Lok, C.-M. Ho, R. Chen, Q.-Y. He, W.-Y. Yu, H. Sun, P.K.H. Tam, J.-F. Chiu, C.-M. Che, Silver nanoparticles: partial oxidation and antibacterial activities. JBIC J. Biol. Inorg. Chem. 12, 527-534 (2007)

52. Y. Lin, R.Y.K. Chang, W.J. Britton, S. Morales, E. Kutter, H.-K. Chan, Synergy of nebulized phage PEV20 and ciprofloxacin combination against Pseudomonas aeruginosa. Int. J. Pharm. 551, $158-165$ (2018)

53. M.P. Benavides, S.M. Gallego, M.L. Tomaro, Cadmium toxicity in plants. Brazilian J. Plant Physiol. 17, 21-34 (2005)

54. P. Mahajan, J. Kaushal, Role of phytoremediation in reducing cadmium toxicity in soil and water. J. Toxicol. 2018 (2018)

55. F. Tanvir, A. Yaqub, S. Tanvir, R. An, W.A. Anderson, Colorimetric detection of mercury ions in water with capped silver nanoprisms. Materials (Basel) 12, 1533 (2019)

56. D. Karthiga, S.P. Anthony, Selective colorimetric sensing of toxic metal cations by green synthesized silver nanoparticles over a wide pH range. RSC Adv. 3, 16765-16774 (2013)

57. S. Jabariyan, M.A. Zanjanchi, Colorimetric detection of cadmium ions using modified silver nanoparticles. Appl. Phys. A. 125, 1-10 (2019)

58. L. Fernández, S. Escobedo, D. Gutiérrez, S. Portilla, B. Martínez, P. García, A. Rodríguez, Bacteriophages in the dairy environment: from enemies to allies. Antibiotics. 6, 27 (2017)

59. N.H. Martin, K.J. Boor, M. Wiedmann, Symposium review: effect of post-pasteurization contamination on fluid milk quality. J. Dairy Sci. 101, 861-870 (2018)
60. F. Oechslin, Resistance development to bacteriophages occurring during bacteriophage therapy. Viruses (2018). https://doi.org/10. 3390/v10070351

61. H. Tan, Y. Chen, Silver nanoparticle enhanced fluorescence of europium (III) for detection of tetracycline in milk. Sensors Actuators B Chem. 173, 262-267 (2012)

62. Y. Ma, H. Niu, X. Zhang, Y. Cai, One-step synthesis of silver/ dopamine nanoparticles and visual detection of melamine in raw milk. Analyst. 136, 4192-4196 (2011)

63. K. Shrivas, N. Nirmalkar, M.K. Deb, K. Dewangan, J. Nirmalkar, S. Kumar, Application of functionalized silver nanoparticles as a biochemical sensor for selective detection of lysozyme protein in milk sample. Spectrochim. Acta Part A Mol. Biomol. Spectrosc. 213, 127-133 (2019)

64. W. Kauzmann, Some factors in the interpretation of protein denaturation. Adv. Protein Chem. 14, 1-63 (1959)

65. I. Heertje, J. Visser, P. Smits, Structure formation in acid milk gels. Food Struct. 4, 10 (1985)

66. D.J. McMahon, H. Du, W.R. McManus, K.M. Larsen, Microstructural changes in casein supramolecules during acidification of skim milk. J. Dairy Sci. 92, 5854-5867 (2009)

67. E. Baranowska-Wójcik, K. Gustaw, D. Szwajgier, P. Oleszczuk, B. Pawlikowska-Pawlęga, J. Pawelec, J. Kapral-Piotrowska, Four types of $\mathrm{TiO}_{2}$ reduced the growth of selected lactic acid bacteria strains. Foods. 10, 939 (2021)

Publisher's Note Springer Nature remains neutral with regard to jurisdictional claims in published maps and institutional affiliations. 